\title{
Three Problems in Co-governance Mechanism
}

\author{
Xuan Jiang \& Dan Liu \\ School of Business Administration \\ Shenyang University \\ Shenyang 110044, China \\ E-mail: jiangxuan05@163.com
}

\begin{abstract}
The co-governance mechanism based on the stakeholder theory is suspected because of "three problems" from mainstream economists. In this article, we adopt many methods such as literature induction and mathematical demonstration to solve three problems in the co-governance mode and offer theoretical proofs for multiple benefit bodies participating co-governance.
\end{abstract}

Keywords: Co-governance, Stakeholder, Three problems

\section{Base of co-governance and the theory of stakeholder}

Since the middle of 1980s, the stock structure of English and US enterprise has extremely dispersed, and the governance mode of "stockholder first" has been suspected extensively because many problems such as the protection of middle and small sized stockholder benefit and anti-annexing, and the problems of interior personnel control and agent costs are more and more serious. After that, the theory of stakeholder occurred, so these theories compose the base of co-governance mode.

The theory of stakeholder roots in incomplete contract theory and modern property right theory. The contract theory thinks that enterprise is a group of connection point and agent relationship of contract, ad every contract participator provides individual resource to the company, and so every one should enjoy the right of equal negotiation (Chen, 1996, p.103-107). At the same time, enterprise is team production in fact, and its essential is the mutual dependence between human resource and non-human resource. To protect the dependence resource to avoid loss, team members should make long-term contract to ensure an anticipated compensation, which offers base for stakeholders' co-governance. However, Hart pointed out that contract was incomplete because the existences such as trading charge, opportunism behavior, human limited sense and information asymmetry. So the property right can be divided into special rights and residual rights. The residual right is the property right which is not definitely confirmed because of the incompleteness of contract, and it is a sort of "state-contingent ownership", i.e. different persons possess residual claim rights and residual control rights under different status (Zhang, 1999, p.52-53). And professor Zhang, Weiying utilized mathematical model to prove it.

According to the theory of contract, all participators of enterprise contract should enjoy the allocation right of enterprise residual rights. However, how to exactly confirm stakeholder of enterprise and avoid the problems of enterprise object diversification and governance efficiency becomes into the focus that mainstream economists suspect the co-governance mode.

\section{Problem of "confirmation of stakeholder"}

The most important reason that mainstream economists criticize the co-governance mode is that it can not confirm enterprise stakeholder. Because the boundary of basic concept is not clear, so the theory of stakeholder can not confirm a specific research object. In fact, according to 27 sorts of representative definition, we found that most scholars tended to confirm the stakeholder from combination association and investment specialization, and they thought stakeholders mean some persons who implemented certain special investment in enterprise, and these persons were associated with enterprise and the association degree was decided by the size of investment specialization.

Therefore, the confirmation of stakeholder is decided by three factors. First, stakeholders must implement special investment to the enterprise. Second, stakeholders assume certain management risk of the enterprise. Generally speaking, the size of risk is closely related with stakeholders' investment specialization degree in the enterprise. Third, according to Freeman's classic definition, stakeholders must be related with the activities of enterprise, and this sort of relationship may be active or passive.

However, the confirmation of stakeholder doesn't mean that the stakeholders' characters are grasped. We still need to 
utilize some dimensions to classify numerous stakeholders. In 1997, Mitchell studied the production and development history of stakeholder theory, and put forward the grading method to confirm stakeholders. Mitchell put forward three characters including validity, right and emergency and graded stakeholders, and he divided stakeholders into three sorts, i.e. (1) confirmed stakeholders, they possess validity, right and emergency for corporate problems simultaneously such as stockholder, employee, creditor and employee, (2) anticipated stakeholders, they keep close association with enterprise and possess two items of above three characters, (3) potential stakeholders, they only possess one item of above three characters (Yang, 1998, p.38-45).

In theory, all owners who fulfill three key factors should participate in corporate governance. However, the actual organizational trading costs are not ignored. The confirmation of reasonable dimensions should follow the balance principle of main principle dimension, and adopt marginal analysis decision method, i.e. when the income brought by the increase of factor is equal with added organizational cost, to decide the optimal dimension of effective governance structure.

Suppose there are $\mathrm{m}$ sorts of factor main bodies in enterprise, and obviously, investor is one necessary main body in enterprise contract, i.e. $\mathrm{n}=1$. However, though stockholders have higher individual incomes, but it will induce the decrease of corporate net income. When the quantity of governance main body is $\mathrm{n}$, the corresponding corporate net income is

$$
\mathrm{s}_{\mathrm{n}}=\int_{0}^{\mathrm{n}}\left(\mathrm{f}_{1}(\mathbf{n})-\mathrm{f}_{2}(\mathbf{n})\right) \mathrm{dn} \text {, and } \mathrm{s}_{1}-\mathrm{s}_{\mathrm{n}}<0 \quad(\mathrm{n}>1)
$$

Where, $f_{1}(n)$ is the benefit of governance, $f_{2}(n)$ is the organizational cost. When $n \rightarrow+\infty$, the cost charge will increase and the income continually decreases, so the net income of enterprise may be negative. That is to say, there is a critical value $\mathrm{n}_{1}$ in $\mathrm{n}$ to make $\mathrm{s}_{\mathrm{n}}>0$ when $\mathrm{n}<\mathrm{n}_{1}$. Professor Lu, Changcong obtained similar conclusion by the social cost analysis method.

So the right main body should be kept in the status of $n_{1}$ in the governance structure. According to the Mitchell grading method and combining with the actual situation of china enterprise governance structure, in this article, we think the optimal dimensions of governance main body should be four to six, and include multiple benefit main bodies such as stockholder, creditor, manager and employee.

\section{Problem of "object diversification"}

In the governance mode of "stockholder first", the corporate object is represented as the value maximization of stockholder. So the corporate object of co-governance is to pursue the stakeholders' benefit maximization, and corporate manager should not only consider stockholders' investment return, but also care for the benefits of stakeholders such as employee and creditor. But the benefit relationships among stakeholders are very complex and contrary, and they can not be quantified exactly, so in practice, they can not be realized and will induce interior manager control. and as one subsystem and the realized base of corporate value, the financial object is to allocate corporate resource and ensure the increase of corporate value. When corporate value can not be quantified, the financial object of enterprise should be the fist selection of the value maximization of enterprise ( $\mathrm{Du}, 2005, \mathrm{p} .7-8$ ). Only the financial object of enterprise is ensured, others' benefits can be realized, i.e. efficiency first and then justice.

In this article, we thought the reason of object problem is the confusion of corporate object and financial object. The corporate object of co-governance is to pursue the stakeholders' benefit maximization, and as one subsystem and the realized base of corporate value, the financial object is to allocate corporate resource and ensure the increase of corporate value. When corporate value can not be quantified, the financial object of enterprise should be the fist selection of the value maximization of enterprise (Du, 2005, p.7-8). Only the financial object of enterprise is ensured, others' benefits can be realized, i.e. efficiency first and then justice.

Though we have confirmed the financial value guidance of co-governance enterprise object, if we have not a specific representative financial index, we will get in the tautology with another form (Zhang, 2002, p.109-112). When enterprise uses all stakeholders' resources to create mutual financial values, all costs relative to resource are individual value factors irrespective with mutual object, and all stakeholder resource costs except for financial value (profit of resource cost) are mutual value objects, which also represents all stakeholders' mutual cake.

From another angle, when putting enterprise on the supply value chain of the whole market, the difference between values obtained from the lower customers and values paid to the upper suppliers is the value distributed in the market value chain, which is called as total value added (TVA), and it belongs to same value connotation denoted from different angles with the "resource cost profit" obtained in the interior value of enterprise, and both of them are financial indexes to represent stakeholders' mutual benefits. Different with the unit value which pursues income maximization of every share in the stockholder value maximization theory, TVA in the logic of stakeholder can not be unified, because different natures of stakeholder resource have not the mutual share base " $n$ " which can be compared (Li, 2003, p.20-21). 
So we think TVA can represent all stakeholders' mutual financial value object and explain the concrete connotation of financial value maximization for enterprises.

According to Zhang, Wuchang's theory, TVA not only extends the range of corporate financial object to all stakeholders, which has more universality and applicability than stockholder value, but also confirms object orientation, which possesses more particularity and maneuverability than corporate value maximization, and it is the development and abstract of object theory between stockholder value maximization and tautology (Zhang, 1999, p.52-53).

Furthermore, TVA pitches stakeholders' mutual financial value, eliminates other non-financial value inducing interior conflict, makes the financial object has specific orientation, doesn't consider complex and diversiform individual factor, and only pitches the object in a total factor and makes it keep its exclusion nature (Zsuzsanna, 1996, p.277-296).

\section{Problem of "co-governance efficiency"}

Relative to the logic of "stockholder first", the theory of stakeholder is more justice and easy to attract resource for enterprises because multiple main bodies' mutual possession enjoins more benefits than individual stockholder. However, discommenders pointed out the co-governance sacrificed the production efficiency of team, dispersed control rights and induced efficiency loss and decision deadlock.

In this article, we think the multiple stakeholders in co-governance could enhance and improve the efficiency of united decision. First analyze the implementation condition that united decision enhances the efficiency, i.e. under what situation, the united decision could exceed individual decision. Suppose the precise rate of every individual decision is $\mathrm{p}(0 \leqslant \mathrm{p} \leqslant 1)$, so the probability of failure is $\mathrm{q}=1-\mathrm{p}$. If many people make collective decision, and form collection decision according to the principle of simple majority. Here, we only take three persons decision as the example (the conclusion can be extended to any multi-main bodies).

Proposition 1. If only everyone's decision precise rate exceeds 0.5 , the effect of united decision will exceed individual decision.

Suppose every decision-maker has equal level and independent decision status, and we don't consider the cost of organization (suppose the income of united decision exceeds the cost of trading). Under the situation of three-person united decision, the probability of precise united decision is $\mathrm{p}^{3}+3 \mathrm{p}^{2} \mathrm{q}$, and the probability of mistake is $\mathrm{p}^{2}+3 \mathrm{p}^{2} \mathrm{q}$. So if we want to enhance the precise rare of united decision, we should fulfill the condition, $\frac{p^{3}+3 p^{2} q}{3 p q^{2}+q^{3}}>\frac{p}{q}$. So we can obtain $\mathrm{p}>0.5$.

If the probability that every decision-maker makes precise decision respectively are $\mathrm{p}_{1}, \mathrm{p}_{2}$ and $\mathrm{p}_{3}$, and take $\mathrm{p}=\min \left\{\mathrm{p}_{1}, \mathrm{p}_{2}, \mathrm{p}_{3}\right\}$, we can obtain similar conclusion.

Proposition 2. Members' decision-making level in the united decision layer can be continually enhanced, and the whole level of united decision can be gradually enhanced.

Suppose the probability of individual precise decision in the first time decision-making behavior is ${ }^{p_{1}}$, the probability of individual precise decision in the second time decision-making behavior is $\mathrm{p}_{2}$, and every decision-maker's study curve could fulfill $p_{2} \geq p_{1}$, and suppose $f(p)=\frac{p^{3}+3 p^{2} q}{3 p q^{2}+q^{3}}$, so when $p>0, f(p)$ is the monotonic increasing function.

Therefore, the sufficient and necessary condition that united decision enhances the efficiency is $p_{2} \geq p_{1}>0$, i.e. if only individual precise decision-making rate is not negative, and individual continually enhance his own precise rate of decision, the efficiency of united decision would be enhanced correspondingly. On the contrary, if the efficiency of united decision wants to be enhanced continually, individual decision-makers should continually study and enhance their own decision-making abilities.

\section{References}

Chenyu. (1996). Enterprise System and Market Organization. Shanghai: Shanghai People's Publishing House. p.103-107.

Duyuan. (2005). Thinking in Corner: Explaining the Governance of Enterprise Stakeholder. Master's Degree Thesis of Ocean University of China. p.7-8.

Li, Xinhe. (2003). Financial Theory of Stakeholder. Beijing: China Financial \& Economic Publishing House. p.20-21. 
Yang, Ruilong \& Zhou, Ye'an. (1998). Enterprise Co-governance Mechanism in the Cooperate Logic of Stakeholder. China Industrial Economy. No.1. p.38-45.

Zhang, Weiying. (1999). Enterprise Theory and China Enterprise Reform. Beijing: Beijing University Press. p.52-53.

Zhang, Wuchang. (2002). Explanation of Economy. Hong Kong: Arcadia Press Ltd. p.109-112.

Zsuzsanna Fluck, Kose John and S. Abraham Ravid. (1996). Privatizing in Stages and the Dynamics of Ownership Structure. Pacific-Basin Finance Journal. Volume 4, Issues 2-3. p.277-296. 